\title{
ABISMAR-SE E ESCREVER-SE
}

\author{
Fábio CAMARGO \\ (Universidade Federal de Uberlândia) \\ fcamargo3@uol.com.br
}

Resumo: Este artigo recorta trechos do Diário, de cartas e de romances de Lúcio Cardoso, para discutir a invisibilidade da sexualidade do autor para a crítica brasileira. Visto durante muito tempo como um escritor católico e intimista, chega a hora de discutirmos algo que não se quer discutido, que se quer silenciado: a sexualidade do escritor percebida em sua escrita. O artigo trabalha sob a perspectiva da crítica biográfica, que aponta para a possibilidade de se juntar em um mesmo espaço a biografia do autor e sua produção literária, sem reduzir uma à outra, mas tomando as duas esferas como conectadas. Desse modo o autor em análise é refletido em sua escrita ao mesmo tempo que reflete sobre ela em sua produção. Tomamos por base a homossexualidade de Lúcio Cardoso, vista por ele como uma monstruosidade em seu tempo, como um ponto de indecidibilidade para ele mesmo e como essa questão aparece na escrita de seus romances e novelas.

Palavras-chave: Lúcio Cardoso. Homoerotismo. Escrita de si.

\section{TO FALL INTO THE ABYSS AND WRITE ONESELF}

\begin{abstract}
This article focuses on excerpts from the Lúcio Cardoso's diary, letters and novels, to discuss the invisibility of his sexuality by the Brazilian critics. Seen for a long time as a Catholic and intimate writer, it's time to discuss something that most of the critics do not want to discuss, that they want to keep silenced: the writer's sexuality in his writing. The article works from the perspective of biographical criticism, pointing to the possibility of joining in a same space the author's biography and his literary output, without reducing one to the other, but taking the two spheres as connected. Thus the author is reflected in his writing while reflecting on him in his production. It relies on Lúcio Cardoso's homosexuality, seen by him as an monstrosity in his time as a point of undecidability for himself and as this question appears in the writing of his novels.
\end{abstract}

Keywords: Lúcio Cardoso. Homoeroticism. Self writing 
Em 1937, Otávio de Faria envia uma carta a Lúcio Cardoso, que versa sobre o medo que ele, Otávio de Faria, tinha de lançar seu primeiro romance, Mundos mortos. Nessa carta, datada de Campo Belo, em 1 de janeiro de 1937, o escritor afirmava:

\begin{abstract}
O romance [Mundos mortos] está pronto. Corrigi-o em dês [sic] dias de trabalho fechado e agora só tocarei nele depois de recolhidas as primeiras opiniões. Estou tremendo. Vae ser mais duro ainda do que pensei. Escândalo e gritos. Católicos e eloipontianus zurrando. Eu, apupado nas ruas, depois, sentado no banco dos réos: imoralista, degenerado, veado, masturbador, louco. A Lúcia, de pé num banco do Passeio Público, declamando: "Esquizóide, pliscroide, epileptizoide..." E o Zé Olimpio, muito amigo, batendo no ombro: "Octavinho, não publique o segundo...É para o seu bem"... (FARIA, 1937, p. 5 - grifos nossos) ${ }^{1}$
\end{abstract}

Dessa carta pode-se apreender o medo estampado na expressão "estou tremendo" que pode ser levado por contiguidade a todos os escritores brasileiros nos anos 30 e 40 de assumir sua sexualidade publicamente. Otávio de Faria morre de medo de todo mundo, desde os seus inimigos, no caso dos "eloipontianos", até os críticos que poderiam dialogar com ele por pertencerem à mesma corrente católica, como é o caso de Lúcia Miguel Pereira. As acusações das quais Faria se ressente são justamente de ser chamado de "imoralista, degenerado, veado, masturbador, louco". Nessa gradação, a última expressão seria o ponto máximo da acusação, enquanto que a primeira seria a menos letal para seu trabalho. Ser imoral, embora não seja bom, ainda é melhor do que as outras três expressões que o escritor elenca em sua carta. Ser degenerado já seria bastante ruim, mas veado e masturbador talvez sejam as mais pesadas críticas que o próprio autor adianta para seu trabalho, que poderia incidir sobre ele mesmo. Seria a execração pública, à qual o autor irá se expor caso insista no lançamento de seu livro. Vocábulos de baixo calão, com consequências terríveis, como a estigmatização da obra é o que esperava esse escritor em seu tempo. Ironia das ironias, Otávio de Faria será execrado na literatura brasileira muito mais por se aliar ao movimento de Plínio Salgado e por seu catolicismo, o qual refletiria em sua crítica considerada fascista e atrasada, conforme João Luís Lafetá em 1930: a crítica e o modernismo, publicado em 1974, do que propriamente por ser homossexual. A crítica fez questão de silenciar-se a respeito

\footnotetext{
${ }^{1}$ Mantivemos a ortografia original contida nas cartas de todos os escritores aqui citados, conforme os documentos constantes do Acervo de Lúcio Cardoso, na Fundação Casa de Rui Barbosa.
} 
dessa parte da vida do escritor, mesmo quando no próprio texto ele se refere a ela.

Com Lúcio Cardoso não teria sido diferente. Sua criação avança na questão de apresentar casos de homossexualismo explícito, como é o caso de Timóteo em Crônica da casa assassinada, publicado em 1959, e de homossexualismo velado, como é o caso de $O$ desconhecido, publicado em 1940. A criação ficcional de Lúcio Cardoso possui esse ponto de indecidibilidade entre mostrar e esconder essa sexualidade diferente, em meio a seus medos mais obsessivos.

Visto durante muito tempo como um escritor católico e intimista, chega a hora de discutirmos algo que não se quer discutido, que se quer silenciado: a sexualidade do escritor percebida em sua escrita. No caso de Lúcio Cardoso, não é novidade para ninguém sua homossexualidade. Apoiando-se muitas vezes na noção estruturalista de que a biografia do autor, algo externo à obra, não importava, a crítica, por tanto tempo quis silenciar sobre sua homossexualidade, devido ao fato de que era uma mancha terrível para os escritores de um modo geral, assim como para a imagem de um escritor como Lúcio Cardoso. Cássia dos Santos, ao analisar a recepção de $O$ desconhecido, depois de apresentar uma crítica de Álvaro Lins, tece a seguinte pergunta:

Se a homossexualidade tematizada na novela não passou despercebida ao meio literário contemporâneo ao escritor, como é possível supor, impõe-se a seguinte conjectura: teria tal fato contribuído para reforçar a atmosfera de má vontade com que muitos já cercavam a obra e a pessoa de Lúcio Cardoso (SANTOS, 2001, p. 89)?

Não preciso tirar Lúcio Cardoso do armário, pois o próprio autor já o havia feito em inúmeras afirmações a respeito de sua sexualidade, a qual ele não dava tanta importância, embora soubesse que ela fazia parte de seu trabalho. O que se pretende aqui é levar o discurso crítico, que sempre o teve por grande escritor e quis silenciar sobre sua sexualidade, para o reconhecimento desse viés temático nos textos do autor e de falar abertamente sobre o tema sem pensar que, tocando nesse assunto, a obra de Lúcio Cardoso seja diminuída. Como Lúcio Cardoso escreveu poucas cartas, pois não gostava de escrevê-las, o jeito é irmos à sua fiç̧ão e ao seu diário, publicado pela primeira vez em 1961, para perceber como essa escrita fala mais do que os críticos quiseram falar. Acredito que não seja nenhuma mancha no currículo de Lúcio Cardoso ser homossexual, embora seu tempo não gostasse dessas figuras ou apenas colocasse esses sujeitos naquele 
que deveria ser seu devido lugar: o escritor estranho, diferente, o enfant gaté, epítetos que foram utilizados para descrever o autor durante muito tempo.

Lúcio Cardoso assume sua escrita autobiográfica em seu diário, o que nos permite perceber muito de sua escrita romanesca, melodramática em sua vida ou vice-versa. A vida escrita de que fala Ruth Silviano Brandão (2006), na qual o autor se escreve inscrevendo-se no mundo. Em um determinado momento de seu diário, Lúcio Cardoso afirmava: "Não tentei me ocultar, nem me fazer melhor do que realmente sou. Nem melhor, nem pior. [...]" (CARDOSO, 1970, p. 169). A ideia de que o diário não traria nada de diferente do que ele realmente era é uma armadilha para todos que querem seguir a escrita de Lúcio Cardoso e pensar nas relações entre vida e obra. Desde o começo é válido destacar o quanto de ficcional há em um diário, principalmente naquele que afirma não querer colocar os fatos cotidianos, mas refletir sobre eles, caso do escritor mineiro aqui analisado. Nesse mesmo trecho o autor continua: "A questão sexual, por exemplo, que alguns leitores provavelmente reclamariam, que adiantaria estampá-la, destituída de força, apenas para catalogar pequenas misérias sem calor e sem necessidade?" (CARDOSO, 1970, p. 169). Ao informar que não irá escrever sobre sua sexualidade, Lúcio Cardoso deu a chave para a crítica de que isso era algo sem importância, embora, em sua escrita ficcional, essa sexualidade indecidível seja bastante representada. Nesse ponto cabe-me perguntar, a partir da carta de Otávio de Faria: o quanto o fato de não estampar a sexualidade, verbalizando isso na escrita do diário, possui de repressão do próprio autor para não ser estigmatizado?

Senão vejamos, como o próprio autor afirma: "só é possível a existência de uma obra de arte, através da obsessão" (CARDOSO, 1970, p. 14). Essa afirmação vai ao encontro do que se quer apresentar neste artigo que diz respeito à criação ficcional de Lúcio Cardoso e seu jogo com o mostrar e o esconder sua própria sexualidade. Desse modo, pistas as mais diversas vão sendo distribuídas pelos diversos textos que nos apontariam para uma sexualidade diferenciada, sem um papel único definido, pois ele mesmo irá afirmar: "Estranho dom: Deus deu-me todos os sexos" (CARDOSO, 1970, p. 295). Suas obsessões serão elencadas pela crítica, como o interesse mórbido, o sangue, as questões metafísicas, a solidão, o gótico, mas a sexualidade ficará de lado por muito tempo, só sendo retirada da condição de lugar intocável pelos primeiros estudos 
sobre homoerotismo nos anos 2000, em um ensaio de José Luiz Fourreaux de Souza Júnior (2002), por exemplo, ou em Eros proibido, de Ricardo Thomé (2009). Esse reconhecimento tardio indica muito da repressão que todos nós da academia sofremos para tratar desse assunto. O crítico que se coloca nesse lugar, assume, portanto sua condição homossexual e aceita como estigma sua função ou isso seria um modo de engajamento político que deixa de lado a literatura? Os críticos heterossexuais não poderiam estudar essa questão? Em pleno século XXI continuamos acanhados, mesmo depois dos inúmeros estudos de gênero. O caso da homossexualidade de Lúcio Cardoso é um mistério para a crítica.

A sexualidade era uma obsessão para Lúcio Cardoso, não só a sua, mas a de seus personagens, senão o que dizer da sexualidade reprimida quase sempre em seus romances e novelas? São inúmeros os casos, que vão desde questões heterossexuais, como o caso de Ida, em Mãos vazias, de Ana, de Crônica da casa assassinada, ou do caso de Inácio Palma, que estupra a mocinha de $O$ enfeitiçado. Na questão especificamente homoerótica, Lúcio Cardoso apresenta o caso que não será confirmado em $O$ desconhecido, no qual o desconhecido, personagem principal, se apaixona, ou encontra-se fascinado pelo adolescente Paulo. Ou o Timóteo de Crônica da casa assassinada e seu travestimento/repressão pela histórica tradição de família. No entanto essa temática sempre ficara à margem no caso da crítica feita ao romance e à novela. Ou se o fizeram, foi apenas tangencialmente. O caso de Crônica da casa assassinada é emblemático. Há muitas resenhas, muitas dissertações e teses, mas poucas se aventuraram pelo tema da homossexualidade como algo central. Além de raramente fazerem menções à sexualidade do escritor.

Novamente retomo a fala/escrita de Lúcio Cardoso em seu diário. Sobre o homossexualismo, ele afirma:

Montherlant diz - e não pode haver testemunho mais insuspeito - que o homossexualismo é a "própria natureza". No que tem razão, pois no ato de duas pessoas do mesmo sexo se unirem, há um esforço da natureza para se realizar até mesmo sem os meios adequados (CARDOSO, 1970, p. 255).

A noção apresentada por Lúcio Cardoso se encaminha para o imaginário do seu tempo sobre a questão. Tomar a opinião de um homossexual para apresentar a homossexualidade como algo da ordem do desvio da norma, daquilo que é 
contra a natureza, mas, ao mesmo tempo, a natureza. Essa explanação vai ao encontro dessa sexualidade que o autor reprimia e ao mesmo tempo exaltava, indecidida entre mostrar-se e esconder-se, reprimida, represada e paradoxalmente sentida na vida e na escrita.

Além da sexualidade que o abisma, o seu catolicismo o obsedava, e ele escreve sobre essa questão em carta a Paulo Hecker Filho, comentando sobre $O$ enfeitiçado, publicado em 1954:

[...] é que você deve imaginar o quanto é dificil [sic] explicar, sobretudo a respeito de um livro que, se por determinados lados póde [sic] ser bastante característico do meu modo certo ou errado de ver as coisas, por outro está longe de ter para mim uma importância [sic] decisiva. É apenas um livro em que pretendi me "esvaziar", não das minhas experiências [sic], que provavelmente nunca se esvaziariam assim, mas de certos fantasmas que, se ainda conservam cacos de catolicismo, fazem-no contra minha vontade e, helas [sic], contra minha vigilância [sic]." (CARDOSO,a, s/d, p.1)

O problema a princípio é apontado como o catolicismo, que se imiscui em sua escrita, conforme o escritor, contra sua vigilância, mas é perfeitamente possível ler outras obsessões do autor com relação à explicação que tenta dar a seu interlocutor. Sua sexualidade, ou sua homossexualidade, também apareceria independente de sua vontade. Contribui para isso a ideia de que ele, o autor, possui uma visão certa ou errada das coisas, bem como a noção de que sua escrita está diretamente ligada às suas experiências, a seus fantasmas que nunca o deixam. Além dos casos muito explícitos em que a homossexualidade aparece, há outros bastante estranhos, como a relação entre Pedro e o marido de Cira em A luz no subsolo, publicado em 1936, ou em $O$ anfiteatro, publicado dez anos depois.

Em outro momento do diário Lúcio Cardoso afirma: "O que me consome, ai, é a extensão da minha solidão" (CARDOSO, 1970, p. 18). A solidão, embora seja algo dos escritores em geral e de seu trabalho de escrita também o é característica do sujeito que se isola por ser diferente. Para Lúcio Cardoso, o lugar que cabe à literatura é "a solidão. A total, a absoluta solidão." (CARDOSO, 1970 , p. 151). Nessa diferença a marcação de espaços entre masculino e feminino é um importante lugar para Lúcio Cardoso, que em uma família composta na maioria por mulheres escolhe um lugar para si a partir do indecidível. Se para a cultura patriarcal, o lugar que compete ao escritor se correlaciona à posição do feminino, para Lúcio Cardoso esse lugar extrapola o da 
mera assunção da profissão para se tornar um problema de gênero do qual ele e outros colegas de geração não conseguem se desvencilhar. Daí o medo de Otávio de Faria em se expor aos olhos de seus contemporâneos e o de Lúcio Cardoso, lançando mão da indecidibilidade em seus romances e novelas, e porque não dizer em seu diário e em suas poucas cartas.

Por isso mesmo o escritor irá afirmar: "Não existo no pleno, e sim no que carece" (CARDOSO, 1970, p. 23). "Tudo em mim é instável, e eu navego sem destino certo" (CARDOSO, 1970, p. 222). Essa carência, aquilo que falta, que é incerto, está muito presente em sua escrita de sujeitos indecisos entre assumir-se como são ou aparentar o que não são. Do mesmo modo sua literatura, iniciada na década de 1930, assume a diferença em seu tempo de produção e na literatura brasileira. Seus tipos mórbidos, doentios, bizarros, diferentes, escancaram a solidão do escritor em meio a seus colegas, à crítica e ao público, indiferentes à sua escrita por muito tempo. E é o próprio autor quem afirma:

\begin{abstract}
Sozinho com aquela luz fumarenta, escutando os mil ruídos da noite lá fora, não pude deixar de sorrir à identidade dessa situação com tantas que procurei descrever em minhas histórias. [*] Muitos dão nomes diferentes a esta forma da energia. E no entanto, o que me interessa não é o prazer, a ação, a glória ou mesmo o amor. É, única e exclusivamente, essa força do absoluto que se chama paixão. Não sei se há em mim um vício central da natureza, sei apenas que é nela, nessa paixão voraz e sem remédio, que encontro afinidade para as minhas cordas mais íntimas (CARDOSO, 1970, p. 35).
\end{abstract}

Há um vício da natureza que incomoda ao autor ou toca seu âmago que segue para sua obra. Essa paixão da qual fala o escritor pode ser lida também como sua sexualidade indecidida que também o faz produzir. Solitário, diferente, apaixonado e homossexual, Lúcio Cardoso fez de sua literatura um espaço tão estranho à literatura brasileira quanto sua vida era estranha a uma grande parte de seus contemporâneos.

Em outra carta a Paulo Hecker Filho, Lúcio Cardoso dá notícia de que a Crônica da casa assassinada já está pronta:

[A crônica] já se acha pronto e talvez lhe agrade mais do que meus livros passados. Foi tratado com mais cuidado, se bem que não me seja possível fugir a este clima por assim dizer vertiginoso, que não é, como você imagina, uma decorrência [sic] da minha facilidade, mas uma expressão muito aproximada do meu íntimo [sic]. Não procuro nada, mas sou mais ou menos aquilo, sem nenhuma intenção de ser assim para ser poético [sic]. Posso lhe garantir, e de um modo um tanto zombeteiro, que não se apaga pouco por esse fútil prazer de jogar com emoções e sentimentos. É verdade que de todos os lados por onde envelheci, envelheci pela minha vertigem, mas ela não foi inventada nem mantida a custo de recursos artificiais. Esforço-me hoje para ser um homem equilibrado - e se a minha lucidez o permite, nem por isto posso transformar essa atitude de conquista num mero esforço literário. O meu 
dom, se ele existe, é o de exteriorisar [sic] esses momentos de tensão. É pouco, mas que é que se há de fazer?" (CARDOSO, b, s/d, p. 1).

Nesse trecho da carta pode-se notar o quanto o íntimo do escritor vai para sua narrativa e o quanto ele afirma ter consciência disso. Seus textos são a soma dele mesmo sem artifícios, sem que ele se exprima a partir de cacoetes, sua literatura está por demais carregada de si; o quanto essa literatura tem a ver com um sentimento de abismar-se na vertigem, de perder-se para se encontrar em sua própria escrita. E a pergunta do escritor é, mais uma vez, a de quem se deixa levar por suas obsessões, por sua vertigem, por sua paixão, por sua sexualidade, indicando que não há outro remédio que não deixar a natureza seguir seu curso, que as coisas se imbricam de tal forma em seu modo de escrever que é impossível separar vida de escrita.

No comentário que tece sobre os michês, os meninos que trucidam velhos nos noticiários de jornal, Lúcio Cardoso não tem nenhum problema em dizer o quanto já travou contato com eles em bares:

Ah, quantas vezes, em mesas de bar, desvendei através de uma ou outra fisionomia calma, o surdo palpitar desses corações à espreita do momento oportuno, desses olhares cegos, voltados para uma única tremenda verdade interior, prontos a se acenderem no instante exato e fulgurante da consumação [...] (CARDOSO, 1970, p. 38).

Seus contatos com esses sujeitos, que parecem viver na sombra, à espera do momento certo de agir, seres estranhos ao mundo dos ditos normais, são apresentados de modo simples, sem velamentos. Em um fragmento do diário, à página 75, Lúcio Cardoso, narra a história de um "menino" que estava preso. $\mathrm{O}$ autor afirma que uma vez "[...] o contemplava, cheio de admiração", enquanto o "menino" quebra o barracão no qual mora e espanca um negro em sua frente, com seus: "Olhos de gato". Esse sujeito seria, segundo o próprio Lúcio Cardoso, motivo para uma peça com esse mesmo nome que nunca saiu da gaveta. A vida vivida, olhada de perto, a vida que corria perigo, poderia, mais uma vez ter sido transformada em ficção. O próprio Lúcio Cardoso afirma: "sou da raça dos que se alimentam de venenos" (CARDOSO, 1970, p. 76). Nesse contato com os michês, a sexualidade que não se queria mostrada é apresentada, não em sua cotidianidade ou em sua explicitação, mas de um modo muito peculiar ao próprio Lúcio Cardoso, como se pode entrever em suas novelas e romances, aquilo que 
Leandro Queiroz (2012) denominou de escrita travestida. Ao assumir se alimentar de venenos, o escritor se coloca no lugar daqueles que lidam com o avesso do que a sociedade quer, assume seu lugar de diferente, estranho, de desviado, que flerta com o mal ao admirar um rapaz maltratar outro em sua frente em um barracão sórdido. Lúcio Cardoso cria, por exemplo, um personagem como o cocheiro Miguel que encarna à perfeição o sádico seduzido pela sua vítima, em $O$ desconhecido. O próprio Lúcio Cardoso é quem afirma em outra passagem de seu diário:

Nada renego da minha natureza, porque daquilo que me faz, de merda e sangue, construirme-ei definitivo e avaro. A mim os lobos e os falcões, a mim os corvos e as bêstas rastejantes. A mim tudo aquilo que consigo transformar em voz. A mim o ser que fui, o que sou, o que não serei mais. A mim os incontinuados traidores. A mim o grande doge que me habita, o carrasco e o vassalo. A mim gemidos e distâncias; reúno as partes dispersas como um grande intruso (CARDOSO, 1970, p. 202-203).

Esse eu transformado em vários assume sua maldade, seu lado esquerdo de um modo que, à primeira vista, parece muito tranquilo e, ao mesmo tempo, sem o confirmar de todo. Desse modo sua natureza, formada de merda e sangue, continua em um lugar entre o céu e o abismo, lugar que cabe àqueles que frequentam os bas fonds da Lapa, representados em $O$ enfeitiçado e Inácio, locais os quais o próprio escritor frequentava e não simplesmente por mero dever de ofício naturalista, mas porque havia um fascínio de sua parte muito grande por esses ambientes. O submundo, a sordidez, a marginalidade fazendo parte da vida daqueles que escolheram viver no gueto, no fundo escuro da vida em sociedade. Locais de homossociabilidade, locais de paixão e perdição em que se pervertiam todos aqueles que se conspurcavam ao toque da mão da noite.

O mal o persegue e ele não se separa do seu lado romancista: "Até agora não consegui afastar-me do mal que escrevo, ou simplesmente representá-lo esse mal sou eu mesmo, e a paixão do homem, nas suas auras e nas suas ânsias, é idêntica à paixão do romancista (CARDOSO, 1970, p. 137). Esse mal é também sua sexualidade, sua forma de viver a vida apaixonadamente, abismando-se vertiginosamente. O mal da escrita que o consome, o mal da vida, as paixões humanas são inegáveis ao escritor, que se (re)escreve, inscrevendose em seu diário, (re)encenando-se. 
Para terminar tomo dois trechos de seus textos, um de $O$ desconhecido e outro de Crônica da casa assassinada respectivamente:

Sacudiu a cabeça e encaminhou-se para o lavatório, onde o esperava uma bacia cheia d'água. Mergulhou nela as mãos e, levantando os olhos, deparou com a sua própria imagem no espelho - um espectro sombrio, um monstro a se agitar no fundo do líquido do espelho azinhavrado. Nenhum movimento, nenhuma contração alterou-lhe 0 rosto (CARDOSO, 2000, p. 14).

- A razão está do meu lado, você vai ver! [...] Um dia você vai ver, Betty. Não há verdade que não venha à tona. [...] Afinal, meu Deus, tanto faz vestido desta ou daquela maneira. Em que é que isto pode alterar a essência das coisas? [...] Houve tempo em que achei que devia seguir o caminho de todo mundo. Era criminoso, era insensato seguir uma lei própria. A lei era um domínio comum a que não podíamos nos subtrair. Apertava-me em gravatas, exercitava-me em conversas banais, imaginava-me igual aos outros. Até o dia em que senti que não me era possível continuar: por que seguir leis comuns se eu não era comum, por que fingir-me igual aos outros, se era totalmente diferente? Ah, Betty, não veja em mim, nas minhas roupas, senão uma alegoria: quero erguer para os outros uma imagem da coragem que não tive. Passeio-me tal como quero, ataviado e livre, mas ai de mim, é dentro de uma jaula que o faço. É esta a única liberdade que possuímos integral: a de sermos monstros para nós mesmos. (CARDOSO, 1996, p. 56-57; grifos nossos).

A monstruosidade da situação coloca esses sujeitos como uma continuidade. Pensando a partir da carta de Otávio de Faria no longínquo ano de 1937, percebo que Lúcio Cardoso vai se apropriando da sua monstruosidade, daquilo que é indecidível, de sua sexualidade, e aprendendo a expor-se, criandose monstro para si mesmo, sua única liberdade. Se o personagem de $O$ desconhecido não se reconhece naquele espelho em 1940, ano da publicação da novela, Timóteo se reconhece como sua própria elaboração, como aquele que aprendeu a ser diferente. A nós da crítica cabe entender que a monstruosidade de Lúcio Cardoso em sua sexualidade considerada por ele mesmo como desviante, longe de manchar seu currículo, ajuda a criar possibilidades de leitura que vão além da mera fofoca e podem contribuir como um construto inerente à sua própria escrita, que a valoriza em sua radical diferença.

\section{Referências Bibliográficas}

BRANDÃO, Ruth Silviano Brandão. A vida escrita. Rio de Janeiro: 7Letras, 2006.

CARDOSO, Lúcio. Diário completo. Rio de Janeiro: José Olympio/INL, 1970.

CARDOSO, Lúcio. Carta a Paulo Hecker Filho. Rio de Janeiro: s/d. (a) Acervo Lúcio Cardoso/Fundação Casa de Rui Barbosa. 
CARDOSO, Lúcio. Carta a Paulo Hecker Filho. Rio de janeiro: s/d. (b) Acervo Lúcio Cardoso/Fundação Casa de Rui Barbosa.

CARDOSO, Lúcio. Crônica da casa assassinada. Edição crítica coordenada por Mario Carelli. São Paulo: ALLCA XX/Scipione Cultural, 1996.

CARDOSO, Lúcio. 0 desconhecido e Mãos vazias. Rio de Janeiro: Civilização Brasileira, 2000.

FARIA, Otávio de. Carta a Lúcio Cardoso. Campo Belo (MG), 1937. Acervo Lúcio Cardoso/Fundação Casa de Rui Barbosa (LC 90 cp). 5 fl.

QUEIROZ, Leandro Júnio Santos. A escrita travestida de desejo: travestimento, identidade e homoerotismo em narrativas de Lúcio Cardoso. Montes Claros: UNIMONTES, 2012. (dissertação de mestrado).

SANTOS, Cássia dos. Polêmica e controvérsia em Lúcio Cardoso. Campinas, SP: Mercado das Letras, 2001.

SOUZA JÚNIOR, José Luis Fourreaux de. (Org.) Literatura e homoerotismo: uma introdução. São Paulo: Scortecci, 2002.

THOMÉ, Ricardo. Eros proibido. Rio de Janeiro: Nova Razão cultural, 2009. 
Artigo recebido em: 12 de agosto de 2014

Artigo aprovado em: 30 de setembro de 2014

\section{Sobre o autor:}

Fábio Camargo é Professor Adjunto do Instituto de Letras e Linguística da Universidade Federal de Uberlândia (UFU) onde é Professor permanente do Programa de Pós-Graduação em Letras/Teoria Literária e Professor colaborador do Programa de Pós-graduação em Letras/Estudos Literários da UNIMONTES. Possui Doutorado em Literaturas de Língua Portuguesa pela Pontifícia Universidade Católica de Minas Gerais (2007) e Mestrado em Literatura Brasileira pela Universidade Federal de Minas Gerais (2000). Possui experiência na área de Letras, com ênfase em Literatura Brasileira, atuando principalmente nos seguintes temas: literatura, práticas de leitura, prática docente, teoria da literatura e representação, literatura infanto-juvenil e literatura e homoerotismo. Atualmente desenvolve pesquisa sobre a produção dos seguintes autores: Machado de Assis, Lúcio Cardoso, João Gilberto Noll e João Guimarães Rosa. 